ARTIGOS

\title{
Ensaio sobre a ideia de tempo em Paulo Freire: a presença da duração bergsoniana
}

\section{An essay on the idea of time in Paulo Freire: the presence of the bergsonian duration}

Resumo: Neste ensaio, examina-se a ideia de tempo em Paulo Freire aproximando sua pedagogia da duração bergsoniana. Parte-se das citações do tempo bergsoniano pelo próprio Freire. O tempo é elemento complexo e rico para investigação. Apresenta-se o tempo como tema epistemológico, situa-se o pensamento de Henri Bergson sobre o tempo e, por meio de um exercício de bricolagem, colocam-se lado a lado os dois autores, em busca da inspiração bergsoniana em Freire. Entende-se inspiração como relação de suporte ao que já existe e descoberta. A afirmação de Bergson de que a ciência nega o tempo e sua concepção da duração como consciência, qualidade, continuidade, criação, mudança e liberdade aproximam-se das alusões de Freire ao tempo, dando força à crítica e ao sentido libertador de sua educação popular. Essa impressão é ilustrada com a menção ao conceito freiriano de inédito viável.

Palavras-chave: tempo, epistemologia, Henri Bergson, Paulo Freire, educação popular 
Abstract: This essay discusses the idea of time in Paulo Freire, approximating his pedagogy to the bergsonian duration. It is based on bergsonian time quotations by Freire bimself. Time is a complex element and is fruitful for investigation. This text presents time as an epistemological theme, it situates Henri Bergson's thoughts about time, and, through an exercise of bricolage, it places both authors side by side, looking for bergsonian inspirations in Freire. Inspiration is here understood as a relationship of support to what already exists and reveals itself. Bergson's statement that science denies time and his conception of duration as consciousness, quality, continuity, creation, changes, and liberty approximate themselves to Freire's allusion to time, reinforcing the criticism and the liberating sense of his popular education. This impression is illustrated by mentioning the freirean concept of untested feasibility.

Keywords: time, epistemology, Henri Bergson, Paulo Freire, popular education

\section{Introdução}

A discussão sobre o tempo convida à ampla contextualização. Nesse sentido, é razoável que investiguemos a ideia de tempo em Paulo Freire, partindo das referências do próprio autor que são remetidas à duração bergsoniana, mas importa que a filosofia de Henri Bergson seja compreendida porque inscrita em perspectiva que lhe confira sentido relacional.

Visitamos a obra dos autores com a certeza de que o encontro de Bergson com Freire se deu, de fato, com a leitura da duração bergsoniana pelo educador brasileiro. Reconhecendo a presença da teorização do filósofo francês no pensamento freiriano, declarada por Freire, desenvolve-se um ensaio com o propósito de aproximar a formulação filosófica de Bergson da construção teórico-conceitual do educador.

Evitando tecer correspondências que atem um ao outro os pensamentos dos autores apreciados de forma a borrar originalidades e limitar profundidades próprias, realizamos um exercício interpretativo sobre a presença do pensamento bergsoniano relativo ao tempo na pedagogia de Paulo Freire, esperando que a abordagem colabore para o sempre necessário (re)conhecimento da obra crítica do educador brasileiro. A pedagogia construída por Freire é fundamental para pensar a educação e sua transcendência social e política, tanto mais quando revisões e críticas são feitas à democracia, a seus sistemas e às suas práticas.

Não se trata de buscar influência como relação hierárquica de subordinação ou encobrimento. Procuramos identificar a presença do pensamento de Bergson em Freire como inspiração, que aqui tem o significado de suporte e também de revelação. Entendemos que um 


\section{pro-posiçōes \\ $e$-ISSN 1980-6248}

http://dx.doi.org/10.1590/1980-6248-2016-0150

autor se torna importante para nós tanto porque vem ao encontro do que já pensamos, como porque nos leva a sistematizações, esclarecimentos e descobertas, de nós mesmos e do mundo.

No texto, indicaremos como a ideia de tempo se inscreve na discussão epistemológica, em seguida se apresentarão Henri Bergson e sua concepção de tempo e duração e, então, informações elaboradas serão transportadas para o pensamento de Paulo Freire. Ao escrever o ensaio, tipo de abordagem cujas características descreve Moisés (2004), tecemos uma reflexão crítica que se realiza no caminhar, formulando livremente impressões, sem pretensão de produzir evidências ou rigidez.

Ao aproximar a duração bergsoniana da teorização freiriana, partimos do discurso do educador, selecionando para análise trechos referentes ou alusivos ao tempo em Pedagogia do oprimido, em que é apresentada sua fundamentação conceitual, e em Pedagogia da esperança - um reencontro com a pedagogia do oprimido. Examinamos como ilustração, o conceito de inédito viável, por sua relevância na obra de Freire e sua evidente concepção temporal.

O ensaio teórico de perspectiva epistemológica, com sua força crítica, é abordagem propícia para temáticas ainda pouco exploradas. Além do que, o tempo, em si, é tema de peculiar riqueza, capaz de conduzir discussões interessantes.

Em essência, destacar o tempo na análise de outros temas que a ele se conjuguem imprime novidade à reflexão. O tempo, como elemento de questionamento, transporta para a investigação a complexidade que lhe é inerente.

\section{A ideia de tempo como questão epistemológica}

Perceber o tempo é, por tudo, questão complexa. O passado não é mais, o futuro ainda não o é, e o presente é fugidio e nos escapa. Em nossa existência, entende Piettre (1997), a familiaridade do tempo convive com sua estranheza.

Não possuindo "ser visível e apreensível", o tempo "seria tanto a fonte da criação, da vida e da verdade como portador da destruição, da morte e do esquecimento". O tempo “engendra e inova, faz perecer e arruína" (Reis, 1994, p. 10). 


\section{pro.posıções \\ $e$-ISSN 1980-6248}

http://dx.doi.org/10.1590/1980-6248-2016-0150

Não é possível observá-lo a distância porque não podemos sair de dentro do tempo. O tempo nos arrasta e ao nosso pensamento e "nos atinge íntima e continuamente", mas não é “"matéria' sensível” aos nossos sentidos senão como "fenômeno totalizante" (Mourão, 2002, p. 101).

Refletir sobre os enigmas do tempo pode provocar "vertigem" e desorientação teórica (Puente, 2010, p. 10). Privar-nos do conhecimento de sua natureza, porém, nos deixará sem a experiência do mundo e sem a história, que tecem nossas relações, nos identificam e orientam. Em sua complexidade, o tempo se oferece como tema interdisciplinar por excelência, o que nos pode levar a considerações significativas, particularmente na perspectiva epistemológica.

Ao discurso e à reflexão, o tempo é reconhecidamente de difícil apreensão. Ele o foi para a filosofia e a ciência clássicas e assim permanece para o conhecimento recente. Ora descrito como linear, circular, espiralado ou ramificado, reversível ou irreversível, exterior ou interior, objetivo ou subjetivo, sucessão ou simultaneidade, movimento ou duração, quantidade ou qualidade, medida ou sensação, a transcendência do tempo prossegue em discussão.

O tempo e sua existência são questões relevantes para pensadores como Aristóteles, Plotino, Averróis, Kant, Bergson, Einstein, Heidegger, Husserl, Kant, Newton, Einstein, Plotino, Prigogine. "De Galileu a Einstein”, segundo Piettre ${ }^{2}$ (1997), a ciência moderna oferece "o espetáculo de uma ordem imutável e intemporal" (p. 56). Aquilo "que o físico mede quando ele mede o tempo é ainda e sempre o espaço" (p. 48). Não mensurável, a duração que compreende a irreversibilidade do tempo e a novidade, "observadas no mundo animado" e "vividas no mais profundo de nós mesmos", quando inventamos ações e "somos os livres autores de nosso futuro, escapam necessariamente ao alcance da inteligência racional, científica e técnica" (p. 49).

No correr do século XX, críticas aos postulados de reversibilidade, controle e previsibilidade da ciência abalaram a ordem paradigmática dominante. Contrariamente à sua exterioridade, negação ou inexistência, uma nova consideração do tempo como história e irreversibilidade, mudança e imprevisibilidade, não determinismo, instabilidade e incerteza surgiu para o conhecimento científico, da combinação entre observações de sistemas sociais e naturais, com as teorias da complexidade (Prigogine \& Stengers, 1984). 


\section{pro-posıções

O desenvolvimento da termodinâmica e os avanços da física cosmológica na compreensão da expansão do universo trouxeram a ideia de uma flecha do tempo que nos leva, e à ciência, para um futuro imprevisível. Somos hoje levados à ideia de que conformamos sistemas abertos em relações de troca permanente com o exterior. Nós, a sociedade que construímos e a natureza da qual somos parte ativa, vivemos da complexidade que criamos.

O reencontro da ciência com o tempo, entendem Prigogine e Stengers (1984), estabelece uma "nova aliança" entre ser humano e natureza.

\section{Henri Bergson: tempo e duração}

O filósofo francês Henri Bergson, dos mais importantes pensadores sobre o tempo, nasceu em 1859 e morreu em 1941, tendo sido laureado em 1927 com o Prêmio Nobel de Literatura.

Segundo Vieillard-Baron (2009), a leitura de Bergson "não coloca em princípio nenhuma dificuldade", já que o filósofo, diferentemente de outros, "se esforçou para falar a linguagem de todos" (p. 7). Sua leitura é acessível e suas quatro obras principais, Ensaio sobre os dados imediatos da consciência, de 1889; Matéria e memória, de 1896; A evolução criadora, de 1907, que o tornou mundial e definitivamente conhecido; e Duração e simultaneidade, de 1922, apresentam consistentemente seu pensamento sobre o tempo.

Barlow (1968) e Vieillard-Baron (2009) entendem que a compreensão da filosofia de Bergson parte da "intuição da duração". A intuição, para Bergson, é a "simpatia pela qual nos transportamos para o interior de um objeto para coincidir com sua qualidade própria", de ser único e inexprimível; e a duração "é um dado interior da consciência", continuidade quando "os momentos se interpenetram e se prolongam uns nos outros, sem que possamos distinguilos", conformando "mudança irreversível” e "imprevisível novidade" (Vieillard-Baron, 2009, p. 108).

A intuição, pensa Deleuze (1999), é método de reflexão de Bergson, compondo-se, como método, de três atos: o que "concerne à posição e criação de problemas" para analisar, o que se refere à descoberta "das verdadeiras diferenças de natureza" das coisas e o da 


\section{pro-posıçōes \\ $e-I S S N$ 1980-6248}

http://dx.doi.org/10.1590/1980-6248-2016-0150

"apreensão do tempo real" para em função dele, e não do espaço, se colocar e solucionar os problemas (p. 8).

Para Bergson (2001), a sobrevivência do passado acarreta mudança por sua acumulação, e, assim, "as circunstâncias podem ainda ser as mesmas, mas já não é sobre a mesma pessoa que agem, porque a encontram num novo momento da sua história" e, por conseguinte, a "duração é irreversível” (p. 17).

“A duração é essencialmente uma continuação do que não é mais no que é. Eis aí o tempo real, percebido e vivido", pelo que "duração implica consciência" (Bergson, 2006, p. 57). A duração é "memória interior à própria mudança, memória que prolonga o antes no depois", impedindo-os "de serem puros instantâneos que aparecem e desaparecem num presente que renasceria incessantemente" (p. 51).

"Sem memória", afirma Coelho (2004), "não há história, não há enriquecimento pessoal" (p. 243). O processo criador "faz parte efetivamente do mundo considerado enquanto totalidade" (p. 244). A história pessoal de qualquer de nós se relaciona à história da cultura em que nos inserimos, "da evolução biológica e do próprio universo" do qual somos herdeiros (p. 243).

“A duração real”, aponta Bergson (2001), “é aquela em que cada forma deriva das formas anteriores, que lhes acrescentam alguma coisa, e explica-se por elas na medida em que pode explicar-se" (p. 318).

"Quanto mais aprofundarmos a natureza do tempo, melhor compreenderemos que duração significa invenção, criação de formas, elaboração contínua do absolutamente novo", indica Bergson (2001, p. 21). “O tempo é invenção ou então não é nada” (p. 301).

No entendimento de Frederic Worms (2004), a intuição da duração consiste na busca de Bergson para esclarecer a "experiência do tempo-realidade" a partir da "constatação da passagem do tempo enquanto fato primordial e originário" (p. 129). Ressalta Worms que "ver o tempo passar" [ênfase no original], em Bergson, "não é a expressão do tédio ou da lassidão diante da repetição do mesmo" (p. 147). É, pelo contrário, "uma surpresa sempre renovada", diante "de uma criação continuada de sentido" (pp. 147-148).

Worms (2004) interpreta que, desde a Evolução criadora, a alegria presente nos textos de Bergson sobre o tempo envolve "uma experiência mística" que se vincula "ao fazer a 


\section{pro.posıções}

http://dx.doi.org/10.1590/1980-6248-2016-0150

consciência humana participar de uma duração" (p. 148). Na filosofia de Bergson, "essa alegria arrancaria a história à repetição do mesmo ou ao simples progresso técnico, para recolocá-la no caminho metafísico que cada um de nós experimenta já em seus atos livres” (p. 148).

Bergson (2011) afirma "a alegria interior" que surge quando "experimentamos como que um espanto por existirmos" (pp. 17-18). Revela-se, com "a ideia de futuro, prenhe de uma infinidade de possíveis" e de "uma imensidão de formas", a esperança (p. 17).

A descoberta da duração por Bergson "resulta da reflexão sobre o tempo físico" (Vieillard-Baron, 2009, p. 17). Numa concepção de ciência, segundo Bergson (2001), o tempo é negligenciável, não é levado em conta, sendo manifestação da degradação de uma essência imóvel, enquanto em uma concepção posterior significa variações quantitativas de um fenômeno, ou de suas partes, que não exprimem a sucessão em sua especificidade qualitativa e a fluidez contínua do tempo, mas permitem a previsão a partir de um assenhoramento em relação aos acontecimentos. "O tempo real, encarado como um fluxo ou, por outras palavras, como a própria mobilidade do ser, escapa aqui ao conhecimento científico" (p. 297).

Bergson (2011) postula que a ciência, ao expressar o tempo em números, nada mais faz do que "eliminar, antes de mais, o elemento essencial e qualitativo" que é a duração (p. 91). Ao lidar com o mensurável, não se trata da duração, "apenas do espaço e de simultaneidades" (p. 91).

"O intervalo da duração só existe para nós, e por causa da mútua penetração dos nossos estados de consciência", exprime Bergson (2011, pp. 91-92). "Fora de nós, encontrarse-ia apenas espaço e, por conseguinte, simultaneidades", a respeito das quais "nem sequer se pode dizer que são objetivamente sucessivas, já que toda sucessão se pensa pela comparação do presente com o passado" (p. 92).

Duração e memória são fluxos indivisíveis, não mensuráveis, próprios de uma criação interior, e sua representação quantitativa realiza-se com sua espacialização, substituindo, assim, o que é vivido pela consciência, por excelência qualitativo, pela quantidade. O espaço, aponta Bergson (1990), "nos é exterior, por definição", permite "levar a divisão tão longe quanto se queira" e, por extensão, quantificar (p. 170). "A distinção entre corpo e espírito não deve ser estabelecida em função do espaço, mas do tempo" (p. 181). 


\section{pro.posıções \\ $e$-ISSN 1980-6248}

http://dx.doi.org/10.1590/1980-6248-2016-0150

A representação espacializada expressa em números permite o isolamento em unidades, a quantificação remete a partes justapostas em instantes num tempo homogêneo representado pela ciência. A multiplicidade dos números é divisível, acomoda-se à matéria e não aos estados de consciência, de multiplicidade qualitativa e indivisível, que conformam a duração, a memória e o tempo em sua concepção de vivência, história, irreversilidade e mudança (Bergson, 1990, 2001, 2006, 2011).

O tempo é "evolução criadora", o universo evolui (Bergson, 2001). "Como o universo no seu todo, como cada ser consciente tomado à parte, o organismo que vive é uma coisa que dura" (p. 25), e "em toda parte em que alguma coisa vive, existe, aberto alhures, um registro no qual se inscreve o tempo" (p. 26).

Segundo Vieillard-Baron (2009), o ponto de partida de Bergson é a "recusa" do "determinismo científico e sua interpretação positivista", que "negam, sem razão, a liberdade humana" (p. 12). O que suporta o determinismo, e a força de controle e previsibilidade que o acompanha, é a capacidade, aponta Coelho (2004), "de calcular o futuro e o passado a partir dos elementos do presente" (p. 235).

A ciência, considera Bergson (2001), "apenas retém das coisas repetição” (p. 37). Somente pode operar "sobre aquilo que se considera que se repita", sobre o que "é subtraído à ação da duração", escapando-lhe o que "exista de irredutível e de irreversível nos momentos sucessivos de uma história" (p. 37).

Acentua Barlow (1968) que, por "mais sólidas", interessaram a Bergson primeiro "as ciências e particularmente as matemáticas", mais do que a filosofia (p. 16). Seu posicionamento crítico diante do determinismo mecanicista o conduziu à reflexão filosófica sobre a duração e o tempo. O que, no entendimento de Coelho (2004), significa atenção ao "dominio da vida interior [ênfase no original]- metafísica e psicologia - que antes não the interessava" (p. 237).

Barlow (1968) registra declaração de Bergson de que seus "livros sempre têm sido a expressão de um descontentamento, de um protesto" (p. 36).

Para Vieillard-Baron (2009) "é sempre aos cientistas [ênfase no original] do seu tempo que as obras" de Bergson primeiramente se endereçam, "e somente num segundo momento 


\section{pro.posıções \\ $e$-ISSN 1980-6248}

http://dx.doi.org/10.1590/1980-6248-2016-0150

aos filósofos" (p. 13). E sua influência aumentou no pós-guerra e penetrou "nos meios artísticos mais do que nos meios científicos" (p. 14).

Destaque-se, então, a importância de Bergson e de sua consideração do tempo, para as obras de Marcel Proust, Giles Deleuze e Ilya Prigogine, respectivamente nas artes, na filosofia e na ciência.

Para Vladimir Jankélévitch (1989), contemporâneo de Bergson e seu importante divulgador, os apontamentos de $A$ evolução criadora vêm "endireitar uma filosofia que caminhava de cabeça baixa" (p. 244). Com Bergson, o ser humano se liberta a partir de "sua implantação e seu enraizamento na existência temporal” (p. 245).

\section{A duração bergsoniana e a ideia de tempo no pensamento de Paulo Freire}

Paulo Freire nasceu em Recife em 1921 e morreu em 1997. Conhecido e respeitado mundialmente como pensador e intelectual, é o mais importante educador brasileiro, tendo, em 2012, recebido o título de Patrono da Educação Brasileira.

Sua teorização foi formulada inicialmente para alfabetização de adultos e depois se notabilizou e se desenvolveu como prática educacional de concepção inclusiva e dialógica que, partindo do respeito à cultura e ao saber popular para a geração do conhecimento, opõe-se ao que ele chama criticamente de "educação bancária", concepção tradicional, elitista e hierarquizada, de caráter autoritário e domesticador (Freire,1978). Freire (2014) enfatiza "o que não é possível é o desrespeito ao saber de senso comum; o que não é possível é tentar superá-lo sem, partindo dele, passar por ele” (p. 116).

Criador de um conhecimento de profundo teor libertador e compromisso com a justiça e a transformação social, Paulo Freire foi perseguido pelo regime ditatorial militar que se instalou no Brasil nas décadas de 1960 e 70 e viveu anos de exílio, quando divulgou suas ideias e exercitou sua prática de uma educação popular em vários países, retornando em 1979. Pelo caráter existencial e político de sua pedagogia na consideração da relação entre liberdade, autonomia, dependência e opressão social, Freire é visto por alguns como idealista, e 


\section{pro-posições}

http://dx.doi.org/10.1590/1980-6248-2016-0150

apontado, de forma acusatória, por quem repudia ideologicamente o pensamento crítico e o debate de ideias, como marxista.

Sobre isso, façam-se devidas observações. De fato, Freire (2014), em sua concepção dialética da educação e do mundo, postou-se sempre contrário ao neoliberalismo, ao neocolonialismo e à opressão social, e, se ele admite a importância histórica da luta de classes, afirma sua dúvida quando essa é referenciada para "explicar tudo, até a cor das nuvens numa terça-feira à tardinha" (p. 125). Relata Freire que dialogou com quem, a partir de Marx, alcançou a "relação dialética mundo-consciência" e não percebeu "as teses defendidas na 'Pedagogia do oprimido" como idealistas, mas "também com quem, preso ao dogmatismo igualmente de origem marxista, mais do que minimizava a consciência, a reduzia à pura sombra da materialidade" (pp. 244-245). O marxismo, diga-se por sua vez, é teoria social crítica relevante que se abre para debate e esclarecimento em qualquer ambiente que se tenha dignamente como democrático.

Para Freire (1978, 1996), a educação é, em si, instrumento de controle e manutenção da ordem política, e é com essa consciência que deve ser considerada quando se deseja praticála com o sentido da transformação social.

Dentre seus livros estão Educação como prática de liberdade, Pedagogia da autonomia, Pedagogia do oprimido e Pedagogia da esperança - um reencontro com a pedagogia do oprimido. São especialmente trabalhadas neste ensaio Pedagogia do oprimido, a principal obra de Paulo Freire, traduzida para vários idiomas e identificada como fonte de articulação teórico-conceitual, e Pedagogia da esperança - um reencontro com a pedagogia do oprimido.

Tema pouco explorado no pensamento de Freire, o termo "tempo" aparece como verbete do Dicionário Paulo Freire, apresentado por Passos (2008a), também autor do texto do verbete "futuro/futurível" (2008b).

Segundo Passos (2008a), "a naturalização do tempo da dominação” enraivece Freire que, no entanto, sabe "dar tempo ao tempo" e, com "paciência histórica" e respeito à marcha de cada um, comungar com a esperança e a utopia (p. 402). "Na cultura do capital", inscrevese a disputa pelo poder de "acumular, deter, retardar ou acelerar o tempo, como forma de dominação política" (p. 402). E, resistindo a esse projeto, “o tempo emerge nas obras de Paulo Freire, como tempo a ser transformado em luta contra a destemporalização, contra sua 


\section{pro·posıções

eternização", constituindo-se como "tempo histórico, incompleto, mutante e passageiro, porque o tempo somos nós com nossas incompletudes" (p. 402). O "tempo vivido" que se tem como "próprio e singular, que se costura na grande ciranda de outros seres semelhantes, cujas temporalidades precisam ser entretecidas numa comunidade de destino e de lutas coletivas" (p. 401). Não nos colocamos "num tempo congelado, exterior à nossa subjetividade; toda vivência temporal nos define pegajosamente por dentro" (p. 402).

O texto sobre tempo do Dicionário Paulo Freire reproduz uma citação sobre "o sentido bergsoniano" da "duração", constante em Pedagogia do oprimido, não se debruçando Passos (2008a), no verbete, sobre a filosofia de Henri Bergson (p. 401). A intenção é, portanto, diferente da deste ensaio sobre a ideia de tempo em Paulo Freire, que é de realizar aproximação reflexiva entre o pensamento de Bergson, sobre a duração, e a pedagogia freiriana.

Reflexos de Bergson parecem, todavia, querer grudar-se às formulações de Passos (2008a) sobre a presença do tempo no pensamento de Freire. Tal se dá quando interpretamos o texto do verbete de modo a remetê-lo ao tempo interior, subjetivo, vivido, com o senso histórico da mudança, descrito por Bergson como duração, opondo-se àquele tempo exterior, eternizado, sem qualidade, remetido ao número e à quantificação, que o filósofo francês relaciona criticamente com a intemporalidade da ciência determinista.

A reflexão de Bergson sobre o tempo transparece em Freire, tornada projeto político de transformação. Ao tratar da esperança, Freire (2014) afirma que não se pode dessa prescindir "na luta para melhorar o mundo, como se a luta se pudesse reduzir a atos calculados apenas, à pura cientificidade", o que seria "frívola ilusão" (p. 15).

A afirmação de Einstein, feita em defesa de suas convicções sobre a física, de que o tempo "não é mais que uma ilusão", é frequentemente citada na discussão epistemológica, tal como registra Piettre (1997, p. 59), e é alvo da objeção de Bergson.

Não pensamos que a esperança, presente como projeto de mundo para Bergson e para Freire, tenha o mesmo significado para ambos. A inscrição da esperança em um tempo que se concretiza em futuro que é novidade, liberdade e criação, vinda de Bergson, pode, no entanto, ter se colocado como inspiração filosófica para o pensamento de Freire, de modo a alimentar o caráter político criticamente libertador de seu projeto educacional. 


\section{pro.posıções \\ $e$-ISSN 1980-6248}

http://dx.doi.org/10.1590/1980-6248-2016-0150

Há que se considerar que existe uma perspectiva dirigida para adiante, que se constrói ao invés de se destruir, implicada em uma visão de tempo que é evolução criadora irreversível, como a de Bergson (2001). Em Bergson (2011), a esperança "é um prazer tão intenso" porquanto "o futuro, que está à nossa disposição, nos surge ao mesmo tempo sob uma imensidão de formas, igualmente risonhas, igualmente possíveis" (p. 17). Em Freire ${ }^{18}$, a esperança "é necessidade ontológica", não é "pura teimosia", mas é "imperativo existencial e histórico" (p. 14).

A citação de Bergson em Pedagogia do oprimido, anotada por Passos (2008a) no Dicionário mencionado, refere-se à afirmativa de Freire (1978) de que "a educação se re-faz constantemente na práxis" e "sua duração [ênfase no original]- no sentido bergsoniano do termo - como processo, está no jogo dos contrários permanência-mudança” (p. 84). Ao contrário da concepção "bancária" que enfatiza a "permanência", prossegue Freire, "a concepção problematizadora reforça a mudança” (p. 84).

A contextualização dada por Freire à citação que faz de Bergson, contrapondo criticamente a educação problematizadora e a bancária, uma como concepção de mudança e a outra como de permanência, autoriza conjecturas sobre a representatividade das propostas do filósofo francês na teorização do educador brasileiro. A remissão explícita ao pensamento de Bergson é corporificada por Freire na consideração crítica do tempo como oportunidade de luta pela libertação e pela transformação social.

A declarada inspiração da pedagogia freiriana pela filosofia bergsoniana se registra mais uma vez com sentido político, quando Freire (1978), também em Pedagogia do oprimido, se refere à ação cultural:

A ação cultural, ou está a serviço da dominação - consciente ou inconscientemente por parte de seus agentes - ou está a serviço da libertação dos homens. Ambas, dialeticamente antagônicas, se processam, como afirmamos, na e sobre a estrutura social, que se constitui na dialeticidade permanência-mudança. Isto é o que explica que a estrutura social, para ser, tenha de estar sendo ou, em outras palavras: estar sendo é o modo que tem a estrutura social de durar, na acepção bergsoniana do termo [ênfases no original]. (p. 212)

Em nota de pé de página, Freire (1978) comenta a citação, esclarecendo que a "estrutura social, portanto histórico-cultural", não se faz da permanência nem da mudança 


\section{pro.posıções \\ $e$-ISSN 1980-6248}

http://dx.doi.org/10.1590/1980-6248-2016-0150

"absolutizadas", mas da "dialetização de ambas", ou seja, da "duração da dialeticidade permanência-mudança" (p. 212).

O texto de Freire permite que considerações sejam, propriamente, feitas quanto à inserção da duração bergsoniana no seu projeto político de educação popular. Interpretando Bergson e Freire, podemos, em um exercício de bricolagem, forjar a impressão de uma compreensão de tempo compartilhada pelos dois pensadores.

Bergson (1990, 2001, 2006, 2011) entende que o tempo flui como continuidade, duração e memória que se realizam como acumulação do passado, revelando-se no presente que já não é mais e remetendo-se ao futuro que virá a ser como liberdade e mudança. Encontrando a "transição ininterrupta, multiplicidade sem divisibilidade e sucessão sem separação”, encontramos “o tempo fundamental” (Bergson, 2006, p. 52).

Para Freire (2014), na realização humana do ser histórico-social, o passado, o presente e o futuro "não são departamentos estanques, sua história, em função de suas mesmas criações vai se desenvolvendo em permanente devenir, em que se concretizam suas unidades epocais" (p. 108). Essas se caracterizam "pelo conjunto de ideias, de concepções, esperanças, dúvidas, valores, desafios, em interação dialética com seus contrários, buscando plenitude” (p. 109). De tal forma, o ontem, o hoje e o amanhã "não são como se fossem seções fechadas e intercomunicáveis do tempo, que ficassem petrificadas e nas quais" estivéssemos “enclausurados" (pp. 108-109). Pois, assim sendo, "desapareceria uma condição fundamental da história: sua continuidade” (p. 109).

“Os momentos que passam", interpreta Worms (2004) sobre o tempo bergsoniano, "não podem se conservar como tais a não ser passando, pode-se dizer, uns nos outros" (p. 135). Os "momentos de nossa vida", diz Bergson (2001), "somos nós mesmos que produzimos", cada um "é uma espécie de criação" (p. 18).

Cabe a nós, entende Freire (2014), remetendo-se a suas reminiscências da infância e do tempo de exílio, perceber o "parentesco [ênfase no original] entre os tempos vividos" (p. 26) e "soldar momentos" (p. 27) com o fim de "desvelar a razão de ser fundamental do modo como nos experimentamos em cada momento" (p. 39).

Para Bergson (2001), a memória não é "faculdade de arrumar recordações numa gaveta ou de inscrevê-las num registro" (p. 16). A memória é “a força interior que permite ao 


\section{pro.posıções \\ $e$-ISSN 1980-6248}

ser vivo libertar-se do ritmo do transcorrer das coisas, reter cada vez mais o passado para influenciar mais profundamente o futuro" (Bergson, 1990, pp. 182-183).

“A acumulação do passado sobre o passado prossegue sem descanso", reflete Bergson (2001, p. 16). "A nossa duração é irreversível" (p. 17). Nossa personalidade "se edifica a cada instante com a experiência acumulada, muda incessantemente", refere (p. 17). "A duração é o progresso contínuo do passado que desgasta o futuro e que incha ao avançar” (p. 16).

\section{Considerações finais: uma menção ao conceito de inédito-viável}

Freire (1978) se posiciona contra os sectarismos e lhes atribui representações de tempo. Os sectários de direita pretendem "domesticar [ênfase no original] o presente para que o futuro" repita este "presente domesticado" [ênfase no original], e os de esquerda transformam "o futuro em algo pré-estabelecido, uma espécie de fado, de sina ou de destino irremediáveis" (p. 23). Para um, "o hoje ligado ao passado, é algo dado e imutável”; e, para o outro, "o amanhã é algo pré-dado, prefixado inexoravelmente" (p. 23). Um e outro "fecham-se em um círculo de segurança [ênfase no original] do qual não conseguem sair", ambos com "a sua verdade" (p.23). Ambos se apropriam do tempo na medida do seu interesse.

Para Bergson (2011), “o determinista”, em sua dificuldade de relacionar-se com a liberdade, "refugia-se no passado ou no futuro" (p. 132). Ou "se transporta, pelo pensamento, para um período anterior e afirma a determinação necessária deste preciso momento, ato do futuro", ou "supondo antecipadamente a decisão realizada, pretende que ela não se podia ter produzido de outra maneira" (p. 132).

As representações de tempo atribuídas por Freire ao sectarismo e por Bergson ao determinismo podem ser remetidas àquela que Verdenal (1974) relaciona com o positivismo comteano em sua "obsessão de riscar a história", quando "a alteridade, a diferença, a alienação", são apagadas para "de novo encontrar a identidade geral das coisas, a repetição do mesmo, em virtude de uma operação mágica do pensamento para exorcizar a mudança” (p. 244). Se existiam diferenças, essas só fazem sentido "congeladas na imobilidade" (pp. 244245). 


\section{pro.posıções \\ $e$-ISSN 1980-6248}

http://dx.doi.org/10.1590/1980-6248-2016-0150

Freire (2014) vê “a compreensão da história como possibilidade e não determinismo" é "ininteligível sem o sonho" (p. 127). Na sua consideração, “a desproblematização do futuro numa compreensão mecanicista da História, de direita ou de esquerda, leva necessariamente à morte ou à negação autoritária do sonho, da utopia, da esperança" (Freire, 1996, p. 73). Os sectários, diz Freire (1978), têm uma "falsa visão da história" porque desenvolvem "formas de ação negadoras da liberdade" (p. 23). De outra forma, aquele comprometido com a "libertação" do ser humano não se fecha em círculos de segurança e "não se sente dono do tempo, nem dos homens, nem libertador dos oprimidos. Com eles se compromete, dentro do tempo, para com eles lutar" (p. 24).

Em Bergson, "a duração é memória, consciência, liberdade”, afirma Deleuze (1999, p. 39). "Liberdade e duração", entende Barlow (1968), são "quase sinônimos" para Bergson (p. 43). No dizer de Bergson (2011), temos dificuldade em "representar a duração na sua pureza original" (p. 85), vivemos mais "exteriormente a nós mesmos" (p. 172), "mais no espaço do que no tempo" e, assim, "somos agidos [ênfase no original] mais do que agimos", porquanto "agir livremente é retomar a posse de si, é situar-se na pura duração" (p. 174). Bergson (2011) conclui que "somos livres quando os nossos atos emanam de toda a nossa personalidade, quando a exprimem, quando com ela têm a indefinível semelhança que por vezes se encontra entre a obra e o artista" (p. 132).

Para Bergson, ser livre é encontrar o tempo, ver-se nele, no tempo vivido, real. Para Freire, o encontro com o tempo tem o sentido de tornar-se ser histórico na luta pela libertação.

Passos (2008b), interpretando o sentido de futuro no pensamento de Freire, aponta que "a postura positivista" não considera "os projetos utópicos" que "geram desequilíbrios, revoluções, tensões, consciência da falta: põem fogo no desejo" (p. 198). O desejo é "fome de ultrapassagem e transcendência", é “tensão" relacionada "ao que está por vir e que, já estando aí, não está em plenitude", sendo, pois, "esperança no futuro, que gera a categoria freireana do inédito viável, que põe toda a realidade dada e estática em movimento, desestabilizando-a" (p. 198). 


\section{pro.posıções \\ e-ISSN 1980-6248}

http://dx.doi.org/10.1590/1980-6248-2016-0150

O conceito de "inédito viável” é apresentado em Pedagogia do oprimido (Freire, 1978, p. 110), e volta a aparecer com distinção em Pedagogia da esperança (Freire, 2014). Por sua marcante conotação de tempo, importa para este ensaio.

Para Nita Freire (Araújo Freire, 2014), inédito viável “é uma das categorias mais importantes" construídas por Paulo Freire (p. 277). Antes de ser apenas expressão sem sentido, segundo a autora, em outra referência (Araújo Freire, 2008), inédito viável é "palavraação" em práxis socialmente transformadora, empregada epistemologicamente por Freire "com enorme carga afetiva, cognitiva, política, epistemológica, ética e ontológica", trazendo no bojo "crenças, valores, sonhos, desejos, aspirações, medos, ansiedades, vontade e possibilidade de saber, fragilidade e grandeza humanas" (p. 231). Intrínsecos ao conceito estão "o dever e o gosto de mudarmos a nós mesmos dialeticamente mudando o mundo e sendo por este mudado" (Araújo Freire, 2008, p. 231).

Inédito viável é conceito freiriano que se refere à perspectiva que se apresenta a nós, como indivíduos e coletividade, quando, a partir da visualização de uma "situação-limite" que foi criticamente percebida, por isso "percebida-destacada" no dizer de Freire, agimos por meio de "atos-limite" para superar condições injustas e sofrimentos que nos são impostos pela opressão social (Freire, 1978, 2014).

Relaciona-se inédito viável, portanto, com outros conceitos de Freire que orientam sua concepção de educação popular (Freire, 1978, 1996, 2014). Com os "temas geradores" cuja construção compõe a percepção crítica da situação-limite, com a "criticidade", com a "conscientização", com a passagem da "curiosidade ingênua" para "curiosidade epistemológica", com o reconhecimento de nosso "inacabamento". Tais conceitos, em consonância, nos remetem a um tempo-futuro de mudança.

Referenciando Pierre Furter (1973), em sua percepção de que o pensamento crítico nos impõe a consideração dos riscos da temporalidade, Freire (1978) afirma que o "pensar ingênuo" se agarra e se ajusta ao espaço garantido da acomodação, ao "hoje normalizado" e, "negando a temporalidade", nega-se a si mesmo (p. 97).

O conceito de inédito-viável remete à "unidade necessária" entre o "presente de lucidez, alegria e transparência do sonho" que nos toma, o "passado de injustiças" que sofremos e destacamos como problema a ser solucionado, e o "futuro de acolhimento 


\section{pro·posıções \\ $e$-ISSN 1980-6248}

http://dx.doi.org/10.1590/1980-6248-2016-0150

mansamente inquietante, de paz de consciência pelo resgate da eticidade e do sentimento" (Araújo Freire, 2008, p. 232). Compõe-se o inédito viável com a "certeza de que tudo vai, precisa e deve continuar no processo ininterrupto de mudanças para concretizarmos o sempre mutante e possível Ser mais em todos e todas nós” (p. 232).

"Ser mais" é concretização da autonomia que "vai se constituindo na experiência de várias, inúmeras decisões, que vão sendo tomadas", consistindo no "amadurecimento do ser para si", processo que é "vir a ser" (Freire, 1996, p. 107).

A ideia de tempo na articulação teórico-conceitual de Freire é fluxo contínuo. As características de sucessão, continuidade, mudança, memória e criação que Coelho (2004) identifica no tempo de Bergson aparecem também em Freire. Podemos perceber no projeto de transformação social da educação freiriana o sentido de multiplicidade qualitativa encontrado na duração bergsoniana, concebida como irreversibilidade, mudança e evolução criadora.

O pensamento de Bergson permanece influente de modo a marcar a vida e a produção de cientistas contemporâneos como Ilya Prigogine, falecido em 2003. Prigogine recebeu o Prêmio Nobel de Química de 1977 por suas contribuições no campo da termodinâmica, particularmente na descrição de estruturas dissipativas que evoluem irreversivelmente para auto-organização distantes do equilíbrio, e foi declaradamente admirador de Henri Bergson.

Citações de Bergson são frequentes na obra de Prigogine (Prigogine \& Stengers, 1986, 1990; Prigogine, 1996), quando explicita a importância do filósofo para seu trabalho científico. O tempo bergsoniano, em sua constatação de que a física negou o tempo e de que a evolução e a mudança integram natureza e vida, inspirou Prigogine na compreensão do papel primordial do não determinismo associado a instabilidade, flutuações e bifurcações, à assimetria entre passado e futuro e à irreversibilidade do tempo para a descrição da vida humana e dos fenômenos que a integram.

À Prigogine (1996), como ele relata, interessava aquilo em que "o tempo desempenhava um papel essencial", assim como "o surgimento das civilizações" ou "os problemas éticos associados à liberdade humana" ou "os sons da música", e esse sentido integra sua compreensão das ciências da natureza (p. 60). Prigogine afirma que os processos irreversíveis descrevem o comportamento da natureza e aqueles reversíveis são exceção. A 


\section{pro-posições \\ $e$-ISSN 1980-6248}

http://dx.doi.org/10.1590/1980-6248-2016-0150

associação entre criatividade e irreversibilidade do tempo é observada desde os sistemas sociais, que são abertos e históricos, trocando permanentemente energia e matéria com o ambiente. Para Prigogine, "a vida só é possível num universo longe do equilíbrio” (p. 30).

Bergson, Prigogine e Paulo Freire, cada qual com a singularidade de sua proposta epistemológica, desejam humanizar o tempo da ciência.

Em texto autobiográfico, Prigogine (2003) explicita que desde sua adolescência recorda de se ter deixado capturar "pelo feitiço de "A evolução criadora" e pela observação de Bergson de que "a duração significa invenção, criação de formas, elaboração contínua do absolutamente novo" (p. 222).

A relação entre Prigogine e a epistemologia da complexidade é reconhecida. A constatação, usando livremente a expressão freiriana, de um "parentesco entre os tempos vividos" (Freire, 2014, p. 26, p.-39) por Bergson, Prigogine e Paulo Freire, possibilita pensar que a complexidade que é percebida no conhecimento produzido pelo educador brasileiro pode se ligar à ideia de tempo que dá sustentação e inspiração para sua filosofia e sua ciência da educação.

Afinal, "tempo e complexidade", revela Prigogine (2003), "são conceitos que intrinsecamente apresentam relações mútuas” (p. 232).

$\mathrm{Na}$ reflexão epistemológica, em sua singular estranheza, o tempo parece submerso e, se o trazemos à tona, floresce.

Não se devemos reduzir a ideia de tempo presente no pensamento de Freire ao que veio de Bergson. Diante da pedagogia de Paulo Freire, de sua generosidade, seu sentido libertador, sua originalidade e propriedade filosófica e científica, não se permitem reduções. A visão deste ensaio é de que a duração bergsoniana participa do pensamento de Freire como inspiração, dando suporte ao que nele já existia, como filosofia, ciência, convicção política, e colaborando na descoberta do que ainda se constituiria. No mais, a discussão apresentada deve colaborar para o entendimento das citações de Freire sobre a duração bergsoniana. 


\section{pro-posıções}

http://dx.doi.org/10.1590/1980-6248-2016-0150

\section{Referências}

Araújo Freire, A. M. (2008). Inédito viável. In D. R. Streck, E. Redin, \& J. J. Zitkoski (Orgs.), Dicionário Paulo Freire (pp. 231-234). Belo Horizonte: Autêntica.

Araújo Freire, A. M. (2014). Notas explicativas. In P. Freire, Pedagogia da esperança - um reencontro com a pedagogia do oprimido (pp. 273-333). São Paulo: Paz e Terra.

Barlow, M. (1968). El pensamiento de Bergson. México: Fondo de Cultura Económica.

Bergson, H. (1990). Matéria e memória - ensaio sobre a relação do corpo como o espirito. São Paulo: Martins Fontes.

Bergson, H. (2001). A evolução criadora. Lisboa, Portugal: Edições 70.

Bergson, H. (2006). Duração e simultaneidade. São Paulo: Martins Fontes.

Bergson, H. (2011). Ensaio sobre os dados imediatos da consciência. Lisboa, Portugal: Edições 70.

Coelho, J. G. (2004). Ser do tempo em Bergson. Interface - Comunicação, Saúde, Educação, 8(15), 233-246.

Deleuze, G. (1999). Bergsonismo. São Paulo: Editora 34.

Freire, P. (1978). Pedagogia do oprimido. Rio de Janeiro: Paz e Terra.

Freire, P. (1996). Pedagogia da autonomia. São Paulo: Paz e Terra.

Freire, P. (2014). Pedagogia da esperança - um reencontro com a pedagogia do oprimido. São Paulo: Paz e Terra.

Furter, P. (1973). Educação e vida. Petrópolis: Vozes.

Jankélévitch, V. (1989). Henri Bergson. Paris: Quadridge/Presses Universitaires de France.

Moisés, M. (2004). Dicionário de termos literários. São Paulo: Cultrix.

Mourão, R. R. F. (2002). Tempo cósmico. In H. Marques (Org.), As visões do tempo (pp. 89110). Belo Horizonte: Autêntica, PUC Minas.

Passos, L. A. (2008a). Tempo. In D. R. Streck, E. Redin, \& J. J. Zitkoski (Orgs.), Dicionário Paulo Freire (pp. 401-403). Belo Horizonte: Autêntica. 


\section{pro-posições}

http://dx.doi.org/10.1590/1980-6248-2016-0150

Passos, L. A. (2008b). Tempo. In D. R. Streck, E. Redin, \& J. J. Zitkoski (Orgs.), Dicionário Paulo Freire (pp. 198-200). Belo Horizonte: Autêntica.

Piettre, B. (1997). Filosofia e ciência do tempo. Bauru: EDUSC.

Prigogine, I. (1996). O fim das certezas. São Paulo: UNESP.

Prigogine, I. (2003). Autobiografia. Margem, 17, 221-233.

Prigogine, I., \& Stengers, I. (1984). A nova aliança. Brasília: Universidade de Brasília.

Prigogine, I. , \& Stengers, I. (1990). Entre o tempo e a eternidade. Lisboa: Gradiva.

Puente, F. R. (2010). O tempo. São Paulo: WMF Martins Fontes.

Reis, J. C. (1994). Tempo, história e evasão. Campinas: Papirus.

Verdenal, R. (1974). A filosofia positiva de Augusto Comte. In F. Châtelet (Dir.), História da filosofia - ideias, doutrinas (pp. 213-246). Rio de Janeiro: Zahar.

Vieillard-Baron, J.-L. (2009). Compreender Bergson. Petrópolis: Vozes.

Worms, F. (2004). A concepção bergsoniana do tempo. Dois pontos: Teoria \& Prática em Educaşão, 1(1), 129-149. Recuperado em 15 de junho de 2016, de http://revistas.ufpr.br/doispontos/article/view/1922/1607

Submetido à avaliação em 22 de novembro de 2016; revisado em 18 de fevereiro de 2017, aceito para publicação em 02 de março de 2017. 